the superficial and two of the deep wire sutures were removed. The wound was thoroughly syringed out with chlorinated soda, and a drainage tube was introduced into the depth of a cavity which the hernia had formed by insinuating itself into the adipose tissue, and which exteoded upward and to the left, external to the recti muscles. Wound packed with iodoform.

The wound was syringed out night and morning, and packed with iodoform, the patient having numerous dejections daily, taking a fair amount of nourishment and stimulants, requiring no opiates, and sleeping the greater part of the time until December 21st, when the remaining wire suture was removed. On taking out the drainage tube a mass of necrosed tissue was removed. Flaps were much undermined.

The temperature remained practically normal, and the wound looked very well at each morning dressing, but an area on the left side seemed to remain in statu quo. On January 5th, in dressing the wound, on introducing the dressing forceps to remove a supposed piece of necrosed tissue a small piece of sponge, the size of a chestnut, was removed. 'This sponge had been packed beneath the flaps to check hæmorrhage at the time of the operation, aud to my chagrin had been inadvertently overlooked in uniting the wound, and explains the persistency of the discharge.

Ou January 28th the temperature rose to $102^{\circ} \mathrm{F}$.; the following day it reached $103.5^{\circ} \mathrm{F}$., and the patient had headache and nausea. The iodoform which had been used in dressing the wound was omitted, and the following morning the temperature was normal, and the headache and nausea had ceased.

The patient's convalescence was delayed, but she left the hospital on March 5th with a perfectly united abdominal wall. She was advised to wear an abdominal support for a time.

'The justifiableness of further operative interference arose when the strangulated intestine had been liberated and returned to the abdominal cavity. Had the case been left to itself at that time we can readily see how difficult it would have been with practically a punctured wound of the abdominal parietes, through which the operator had been able to relieve the constriction, to have prevented the natural drain of fluids into the abdominal cavity. For this penetrating wound of the abdomen was substituted an abdominal section, five inches in length, in the median line, the adherent omentum was removed, the abdominal walls, including the peritonæum, were subsequently brought accurately in apposition, thus making an effort which, in this instance, was successful, to render permanent the relief to this ever-present danger.

- According to the Lancet, at Bridgewater, Eng. land, on the 5th of September, a laborer fell into a trance, and his wife, thinking he had died suddenly, made preparations for the funeral. The vicar, however, on being informed of the facts, inspected the supposed corpse, and refused to allow it to be buried, since it was not cold enough to satisfy him that actual death had taken place. The body was placed in a coffin and conveyed to the church, where it was frequently visited by the vicar and others. On the 8th of September a slight movement occurred, the man was removed to bed, and has since slowly recovered.

47

\section{THE CURE OF CROOKED NOSES BY A NEW METHOD. ${ }^{1}$}

BY JOHN B. ROBERTS, M. D.

I PResent this patient to the Society to show the manner in which I treat the very disfiguring lateral deformity of the nose, so often seen after falls or blows which have fractured the septum and cartilages. The method is, I believe, original. It is certainly attended with very little inconvenience to the patient, who, after recovering from the anæsthetic, can at once attend to his occupation without wearing any apparatus to call attention to the surgical procedure by which his crooked nose is being made straight and shapely. The usual advice given to patients with deformed noses, from nasal fracture sustained in childhood or later, is to undertake no surgical treatment, but to become reconciled to the disfigurement of feature as best they may. This is, I am sure, improper advice. The cosmetic objection to a crooked nose is cogent ; and, moreover, obstruction of one nostril, from the displaced cartilages, is a frequent accompaniment of such lateral deviation of the tip of the nose.

This man sustained, ten years ago, a fall upon his face, from which he recovered with the end of the nose bent to the right, and with considerable obstruction of the left nostril. I operated on him day before yesterday. You see now a straight nose, and nothing to call attention to the operation except a small piece of black court-plaster a little to the right of the nasal bridge. Just within the right nostril close inspection reveals the head of a pin, situated on the side of the septum, near the columella. The method of operation, therefore, is certainly not objectionable on account of making the patient unpleasantly conspicuous during treatment. This evening I merely wish to show the man, and refer to my method of dealing with such cases, because at a later time I hope to bring the subject of curing nasal deformities before the Society in a more formal and elaborate manner. Then, I may have no patient undergoing straightening of the nose to illustrate the remarks.

Replacement of the deformed structures in this case was very simple. With a scalpel introduced through the left nostril I perforated the cartilaginous septum at its upper and back part, and made a long incision through it in a direction downwards and forwards. 'This permitted me to push the whole cartilaginous portion of the nose to the left, and overcome to a great extent the lateral deformity. To retain the parts in this position $I$ introduced a steel pin, about one and one fourth inch long, into the right nostril, and passed it completely through the anterior and upper segment of the divided septum, near the columella. Having the movable portion of the septum thus transfixed, I was enabled, by carrying the head of the pin to the left, to move the anterior part of the nose to the left, and retain it there by imbedding the point of the pin deeply in the immovable cartilaginous septum and mucous membrane at the back of the left naris. In other words, I incised the deformed cartilage, and pinned it in position very much as you would pin a flower in the button-hole of a coat. There still remained a little deflexion of the end of the nose to the right, which seemed to be due to mal-position of the lateral cartilage

1 Read before the Philadelphia County Medical Society, September 17,1884 . 
close to the riglt nasal bone. With a tenotome in the right nostril, I pared the cartilage loose, without perforating the skin, and pinned the parts over to the left by a second pin inserted from the cutaneous surface of the dorsum on the right of the median line. The point of this pin was fixed by having its point imbedded in the tissues of the lett naris. It is the head of this second pin that is covered by the small square of court-plaster. 'The correction of the angular deformity of the septum removed most of the occlusion of the left nostril, which had greatly annoyed the patient.

I have thus given an idea of the method, which has, I believe, great capability for relieving unsightly nasal deformities. 'The novelty consists merely in piuning the parts in position until cicatrization takes place. Endeavors have occasionally been made, as by Mr. Adams, Dr. Weir, and others, to hold deflected noses in position, after operation, by the use of clamps, rods attached to the forehead, adhesive plaster plugs, and similar devices. All of these are objectionable, because so conspicuous and troublesome, and would probably be adopted only in instances of great deformity. 'The pin method, however, leaves no noticeable scar, is not troublesome to the patient, and is applicable, therefore, even to those slight defurmities, whose chief annoyance is an æsthetic and cosmetic one. I leave the pins in position for about two weeks.

A few years ago Dr. Mason, of Brooklyn, recommended the use of steel needles to hold the nasal bones in position. when, after recent comminuted fracture, it was difficult to keep the tragments sufficiently elevated. He transtixes the nose below the depressed fragments, and carries a piece of plaster or a rubber band across the external surface of the bridge from one end of the needle to the other. The needle acts as a girder to tie the base of the nasal arch and prevent its falling in. This is a different use of the pins or needles from that which $I$ am describing, and for a different purpose.

I have pins of lengths varying from one inch to two and one fourth incles, and with flat heads, so that there will be little projection under the court-plaster to attract attention when the patient is in public. The heads are square, that the pins while imbedded may be, if necessary, readily rotated by the fingers.

When the deformity is in the osseous portion of the nasal bridge section with small chisels is usually necessary. Discussion of this topic, however, would carry me beyond the limits of the present subject.

Free incisions are essential in obtaining good results in cases of nasal deformity such as was exhibited by this patient. The surgeon must not spare the knife and thereby spoil the nose. Secondary operations may sometimes be required to get the best results. If a simple incision did not allow proper adjustment I should excise portions of the cartilage with the oval punch or the scalpel, or make multiple stellate incisions with the stellate punch, and so produce general flexibility of the cartilage.

Recurrence of deformity would, I think, be less likely to occur after free incision, pinning, and cicatrization than after simple dilatation with or without incision with the stellate punch.

- A recent writer iu the Medical News (August

\section{NOTES OF A CASE OF POISONING FROM} MRS. WINSLOW'S SOOTHING SYRUP.'

BY A. B. HIRSH, M. D.

WiTh the object of adding my quota to the list of serious accidents resulting from the indiscriminate sale of secret medical preparations, I have gathered the notes of the following case :-

Mrs. A. H. L. took her twenty months' old boy to visit some friends, and while there they (all unknown to her) fed him some unpeeled apple and other indigestible material. Being colicky all that night and next morning she was persuaded by a "friend" to purchase a two-ounce vial of the nostrum sold as "Mrs. Winslow's Soothing Syrup," and of this gave him half-teaspoonful doses, as the directions called for, although she insists half of each quantity was spilt through his struggling.

He took, therefore, the first dose at four o'clock on Sunday afternoon (August 24th) and, there being no effect, another at eight ; thell dozing but not sleeping from this time till three-next morning, the pain starting him again to whining, he was dosed at five; still crying on, three quarters of an hour later the final similar amount was administered. The mother soon became alarmed at the marked stupor which had now set in. He would touch none of the breakfast placed before him, Mrs. L. said ; although sitting upright in his high chair ${ }_{j}$ his head hung listlessly, and he recognized nobody.

I saw bim at 7.45 A.M. and found marked symptoms present of poisoning by some narcotic drug. 'The pupil was contracted down to the typical pin-head; stupor was unmistakable ; respiration was very slow, gasping, and shallow, while at irregular intervals he would take two or three rapidly succeeding deep sighs; the pulse was rapid and small; the extremities were cold throughout the case. 'Taking all these symptoms into consideration, aud the fact that the breath bore the peculiar odor of au opiate, I felt warranted in treating the case for one of poisoning by some preparation or derivative of that drug.

'The stomach and bowels were emptied at once ; frequent cold sponging was ordered, with wet cloths placed on the nape of the neck whenever great trouble existed in keeping him awake. 'Tr. belladonna was given hourly in aqueous solution. The parents were directed to keep him awake by all means.

By noon he would begin to lift the eyelids a little, but relapsed into a sort of doze by two P.M. Iespite all their efforts he fell once more into a stupor by six. Calling about this time, I insisted on the mechanical exercises being continued, feeling encouraged by the somewhat improved breathing, aud that I succeeded, a little while later, in arousing him. As the pupil had now slowly begun to dilate, the medicine was ordered to be given every half hour, or twice as often as before. By eleven he began to lighten up, and on calling, half an hour later, I found him languidly trying to push his ball around the table upon which he sat. The pupils were widely dilated, and respiration free. He was allowed to sleep, with slight interruptions, from midnight until six A. M., after which the child showed his great thirst by frequent demands for ice-water. Incoordination of the voluntary muscles now became noticeable, and continued until next morning. A typical

1 Read beore the Philadelphia County Medical Society, Septem- 